\title{
Alternating Current Electrohydrodynamic Printing of Microdroplets
}

\author{
Gao-Feng Zheng, ${ }^{1}$ Hai-Yan Liu, ${ }^{1}$ Rong Xu, ${ }^{1}$ Xiang Wang, ${ }^{1}$ Juan Liu, \\ Han Wang, ${ }^{2}$ and Dao-Heng Sun ${ }^{1}$ \\ ${ }^{1}$ Department of Mechanical and Electrical Engineering, Xiamen University, Xiamen 361005, China \\ ${ }^{2}$ Guangdong Provincial Key Laboratory of Micro/Nano Manufacturing Technology and Equipment, \\ Guangdong University of Technology, Guangzhou 510006, China
}

Correspondence should be addressed to Juan Liu; cecyliu@xmu.edu.cn

Received 9 February 2014; Revised 3 May 2014; Accepted 5 May 2014; Published 26 May 2014

Academic Editor: Huarong Nie

Copyright (c) 2014 Gao-Feng Zheng et al. This is an open access article distributed under the Creative Commons Attribution License, which permits unrestricted use, distribution, and reproduction in any medium, provided the original work is properly cited.

This paper discusses the technology of orderly printing of microdroplets by means of electrohydrodynamic print (EHDP) with alternating current $(\mathrm{AC})$. The $\mathrm{AC}$ electric field induces charges to reciprocate in the electrohydrodynamic charged jet and generates periodic alternation of electric field force, which facilitates the breakup of charged jets and injection of microdroplets. Microdroplets with a diameter of $100 \sim 300 \mu \mathrm{m}$ can be printed with a frequency of $5 \sim 25 \mathrm{~Hz}$ via AC EHDP. Effects of process parameters on the microdroplet injection behaviors were investigated. A higher frequency of applied AC voltage led to a higher deposition frequency, but smaller diameters of printed droplets. Deposition frequency and droplet diameters increased with the increase of duty cycle and solution supply rate. AC pulse voltage has provided a novel way to study the control technology in EHDP, which would accelerate the application of inkjet printing in the field of micro/nanosystem production.

\section{Introduction}

Owing to advantages of bendableness, low cost, robustness, and lower power consumption [1], flexible electronics have great potential application in the fields of information $[2,3]$, energy [4-6], lithium-ion [7, 8], health [9], and micro/nano system $[10,11]$, among others. Utilization of organic functional materials and flexible substrates are the trademarks for flexible electronics which, however, are incompatible with conventional IC fabrication technology [12] and call for novel fabrication methods $[13,14]$. As a high efficiency, lowcost, low-waste, and noncontact fabrication process, inkjet printing has been regarded as one of the most potential technologies for large scale manufacturing of flexible and organic electronics $[15,16]$. Inkjet printing does not need stencil-plate and etching process; therefore, electronic devices with complex patterns or three-dimensional structures can be printed directly and quickly $[17,18]$.
Conventional inkjet printing technologies, which rely on inner pressure generated by thermal bubbles or the piezoelectric pump, have limitations in reducing the droplet size and line width of printed patterns [19]. Electrohydrodynamic print (EHDP) utilizes external electric field force to stretch viscoelastic solution. EHDP jet was ejected from the tip of Taylor cone under the spinneret [20-22]. The diameter of the EHDP jet is independent of the inner diameter of the spinneret, which is a great advantage to reduce the size of printed micro/nanostructures. Near field electrospinning [23] (NFES) takes the advantage of stable straight jet outside the spinneret to produce precise deposition of printed micro/nanostructures. According to NFES theory, micro/nanodroplets [24] can be deposited accurately on the collector through the EHDP technology, the same as nanofibers $[25,26]$.

Not only direct current (DC) high voltage sources, but also multistep pulse voltage sources [27] and alternating 


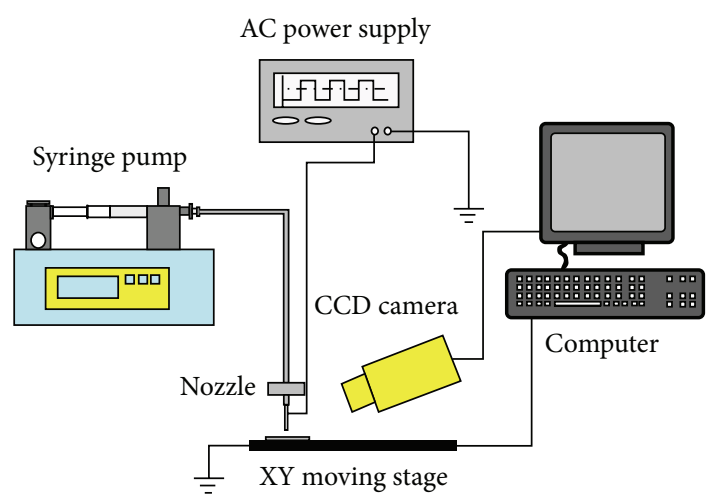

Figure 1: Schematic diagram of AC electrohydrodynamic printing experiment setup.

current (AC) voltage sources [28] can be used as the high voltage sources for EHDP. Espín et al. [29] discovered that, under AC electric fields, the maximum growth rate and corresponding wave number can be expressed as a function of the oscillation amplitude and frequency. Larsen et al. [30] disclosed a patent that employs an AC voltage source in the EHDP apparatus to improve the control technology of fiber and particle printing. Kessick et al. [31] reported that the AC high voltage source changes the charge transfer characteristics of the EHDP jet and reduces charge repulsive force between the solution jet and the substrate, which improves the positioning precision of printed micro/nanostructures. Ghashghaie et al. [32] reported that AC electric field induces charges to redistribute on the substrate, which helps the parallel deposition of $\mathrm{ZnO}$ nanofibers. Nguyen [28] used single AC electrode to print silver paste pattern that overcame the jet drawback of conventional DC EHDP and found out that AC voltage also was propitious for increasing the deposition frequency. The control technology of AC EHDP under near field was different from that of conventional DC EHDP. Thus, further studies on the injection and deposition behaviors of microdroplets under AC electric field should be carried out.

In this paper, AC pulse voltage was utilized to print microdroplets, and the injection and deposition behaviors of charged droplets were studied. We also discuss the effects of process parameters on the morphology, diameter, and deposition frequency of printed microdroplets.

\section{Experiment Details}

The schematic diagram of experimental setup was illustrated in Figure 1, where high AC power sources (DW-P503LACDE, China) were used to generate electric field. A silicon wafer used as grounded collector was fixed on an X-Y motion stage (Googol GXY1515GT4, China). The motion velocity of the collector ranged from $2 \mathrm{~mm} / \mathrm{s}$ to $40 \mathrm{~mm} / \mathrm{s}$, and motion track can be controlled by the host computer. Stainless nozzle (inner diameter $=62 \mu \mathrm{m}$, outer diameter $=90 \mu \mathrm{m}$ ) was used as the EHDP spinneret, and the distance from spinneret to the collector was $2 \mathrm{~mm}$. Polymer solution was continuously

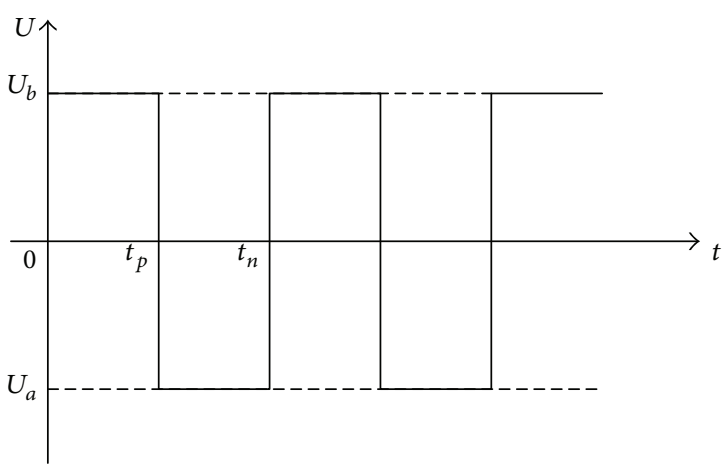

FIGURE 2: Wave shape of AC pulse voltage.

delivered to the spinneret by a syringe pump (Harvard 11 Pico Plus, USA). A CCD camera (uEyeRe UI-2250-C, German) was used to observe and record the injection and deposition process of the EHDP jet. The droplet size can be measured through the CCD pictures with scale with the help of image processing software ImageJ. Polyethylene oxide (PEO, $M_{W}=$ $300,000 \mathrm{~g} / \mathrm{mol}$ ) solution in mixed solvent of deionized water and ethanol $(v / v=60 / 40)$ was used as injection materials. The concentration of PEO solution ranged from $1 \mathrm{wt} \%$ to $5 \mathrm{wt} \%$. Before starting the experiment, the silicon wafer substrate was ultrasonically cleaned in the mixed solution of deionized water and acetone for $20 \mathrm{~min}$; and then the cleaned silicon wafer was dried by a hot air blower. The wave shape of AC pulse voltage used in the experiments was shown in Figure 2; $U_{a}$ and $U_{b}$ referred to the negative amplitude and positive amplitude of AC pulse voltage, respectively. The effects of AC pulse voltage on the EHDP injection process were studied by varying the voltage amplitude, the duty cycle, and the frequency.

In these experiments, the deposition frequency of microdroplet was defined as $f_{\text {dep }}=v_{\text {col }} / l$, where $v_{\text {col }}$ was the collector motion velocity (unit for the collector motion velocity was $\mathrm{mm} / \mathrm{s}$ ) and $l$ was the center-to-center distance between two adjacent printed droplets (unit for the distance was $\mathrm{mm}$ ). Both the average center-to-center distance $l$ and the printed droplet diameter $D_{\text {dep }}$ were calculated from 50 data points, respectively.

\section{Results and Discussions}

The injection and deposition behaviors of AC EHDP droplets were studied further to improve the control technology of microdroplet injection. A series of experiments were performed to investigate the effect of AC voltage amplitude $U_{a}$, duty cycle ratio $\rho$, frequency $f_{\text {app }}$, and solution supply flow rate $Q$ on the microdroplet injection behaviors.

3.1. AC Voltage Amplitude. The effect of applied voltage amplitude on the injection process was studied first. The concentration of $\mathrm{PEO}$ solution $C, \mathrm{AC}$ voltage frequency $f_{\text {app }}$, duty cycle ratio $\rho$, and solution supply rate $Q$ were $3 \mathrm{wt} \%, 20 \mathrm{~Hz}, 50 \%$, and $30 \mu \mathrm{L} / \mathrm{hr}$, respectively. Experimental results showed that $U_{b}=2.8 \mathrm{kV}$ could build up the stable 


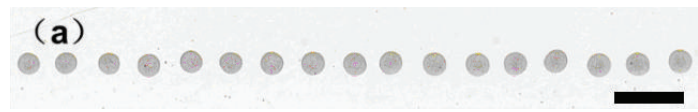

(a)

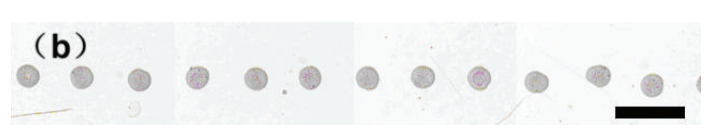

(b)

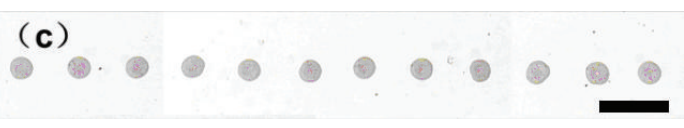

(c)

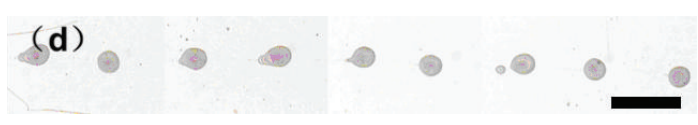

(d)

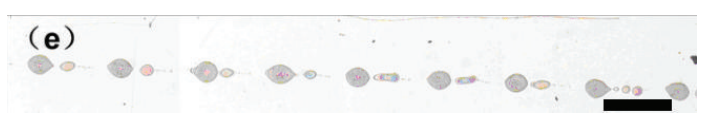

(e)

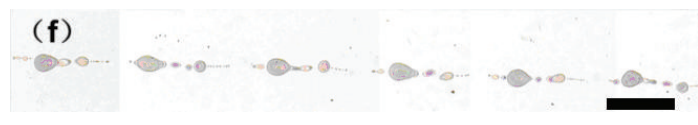

(f)

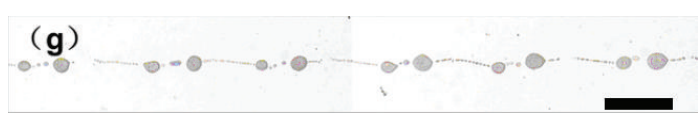

(g)

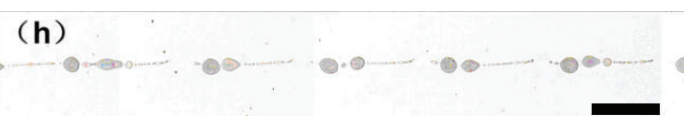

(h)

FIGURE 3: Printed droplets under AC voltage with different negative AC voltage amplitude $U_{a}$. Negative AC voltage amplitude and collector motion velocity were (a) $U_{a}=0 \mathrm{kV}, v_{\mathrm{col}}=10 \mathrm{~mm} / \mathrm{s}$;

(b) $U_{a}=0.5 \mathrm{kV}, v_{\text {col }}=14 \mathrm{~mm} / \mathrm{s}$; (c) $U_{a}=0.75 \mathrm{kV}, v_{\text {col }}=14 \mathrm{~mm} / \mathrm{s}$;

(d) $U_{a}=1 \mathrm{kV}, v_{\text {col }}=20 \mathrm{~mm} / \mathrm{s}$; (e) $U_{a}=1.25 \mathrm{kV}, v_{\text {col }}=20 \mathrm{~mm} / \mathrm{s}$;

(f) $U_{a}=1.5 \mathrm{kV}, v_{\mathrm{col}}=30 \mathrm{~mm} / \mathrm{s}$; (g) $U_{a}=1.75 \mathrm{~V}, v_{\mathrm{col}}=30 \mathrm{~mm} / \mathrm{s}$;

(h) $U_{a}=2 \mathrm{kV}, v_{\text {col }}=30 \mathrm{~mm} / \mathrm{s}$. The scale bar is $1000 \mu \mathrm{m}$.

cone-jet injection. During the experimental process, the positive AC voltage amplitude $U_{b}$ was fixed at $2.8 \mathrm{kV}$, and then the negative AC voltage amplitude $U_{a}$ was varied to study the effect of applied voltage amplitude on the AC EHDP injection process. Droplets printed under different negative AC voltage amplitude $U_{a}$ were showed in Figure 3. In order to capture clear pictures of printed droplets, the collector motion velocity $v_{\text {col }}$ was controlled to adjust the space between two adjacent printed droplets according to the deposition frequency $f_{\text {dep }}$. EHDP jet had been broken into microdrops before deposition on the collector, so the collector motion velocity would not affect the deposition frequency and the volume of EHDP droplets [33].
Negative voltage generated a reverse force and the charged jet shrank back, which helped the EHDP jet break into droplets. When the negative AC voltage amplitude was lower than $1 \mathrm{kV}$, droplets can be printed without satellite dots, as shown in Figures 3(a) 3(c). When the negative AC voltage amplitude $U_{a}$ varied from 0 to $1 \mathrm{kV}$, the average droplet diameter $D_{\text {dep }}$ and the deposition frequency $f_{\text {dep }}$ remained relatively constant. $D_{\text {dep }}$ and $f_{\text {dep }}$ of printed droplets were $250 \mu \mathrm{m}$ and $24 \mathrm{~Hz}$, respectively. When the negative AC voltage amplitude $U_{a}$ increased further, the charged jet was drawn back by the reverse electric field force more quickly. The higher recovery rate caused the jet to break into more satellite dots due to the larger Weber number. Satellite dots were deposited along the collector motion track, as shown in Figures 3(d) 3(h). The number of satellite dots between two adjacent printed droplets increased along with the negative AC voltage amplitude $U_{a}$, due to the larger reverse force and speed. The printed droplet diameter decreased with the increase of negative AC voltage amplitude $U_{a}$, due to the constant solution supply rate $Q$ and a higher deposition frequency $f_{\text {dep }}$. On the other hand, the Coulomb repulsive force among the liquid droplet was another reason for the satellite dots. According to the theory simulation, positive voltage period would induce positive charge assembled on the surface of polymer jet, but negative voltage would induce positive charge. The surface charge density increased with the increase of applied voltage amplitude [34, 35]. Theory simulation results showed that surface charge density of liquid jet increased from $1.28 \mathrm{C} / \mathrm{m}^{2}$ to $80.8 \mathrm{C} / \mathrm{m}^{2}$, when applied voltage amplitude increased from $0.5 \mathrm{kV}$ to $2 \mathrm{kV}$. Larger surface charge density also increased the Coulomb repulsive force among the liquid droplet, which promoted the breakup of charged droplet.

3.2. Duty Cycle Ratio. The microdroplets printed under different duty cycle $\rho$ of $20 \sim 70 \mathrm{wt} \%$ were shown in Figure 4. The negative AC voltage amplitude $U_{a}$, positive AC voltage amplitude $U_{b}$, AC voltage frequency $f_{\text {app }}$, PEO solution concentration $C$, and solution supply rate $Q$ were $1.0 \mathrm{kV}$, $2.8 \mathrm{kV}, 20 \mathrm{~Hz}, 4 \mathrm{wt} \%$, and $60 \mu \mathrm{L} / \mathrm{hr}$, respectively. The positive AC voltage played the role to stretch the viscoelastic solution to produce the charged jet. The charged jet was stretched and accelerated toward the collector by the positive electric field force. A higher duty cycle $\rho$ led to longer charging time, larger charge density, and higher motion speed of EHDP jet, which would help the jet break up into microdroplets.

The deposition frequency $f_{\text {dep }}$ and the droplet diameter $D_{\text {dep }}$ increased with the increase of the duty cycle $\rho$; the relationship was shown in Figure 5. The droplet diameter $D_{\text {dep }}$ increased from 150 to $190 \mu \mathrm{m}$ due to longer stretching time under the positive voltage, when the duty cycle $\rho$ increased from 20 to $70 \%$. As shown in Figure 5, the deposition frequency $f_{\text {dep }}=10 \mathrm{~Hz}$ was one half of the $\mathrm{AC}$ voltage frequency $f_{\text {app }}$, when duty cycle $\rho$ was smaller than $60 \%$. The deposition frequency could be rewritten as $f_{\text {dep }}=$ $f_{\text {app }} / 2$. However, when the duty cycle $\rho$ increased to $70 \%$, the deposition frequency $f_{\text {dep }}$ increased sharply to $15 \mathrm{~Hz}$, where $f_{\text {dep }}=3 / 4 f_{\text {app }}$. 


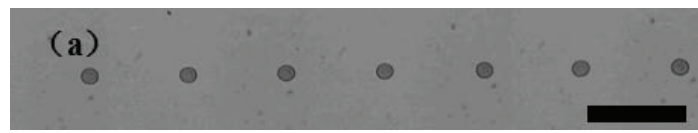

(a)

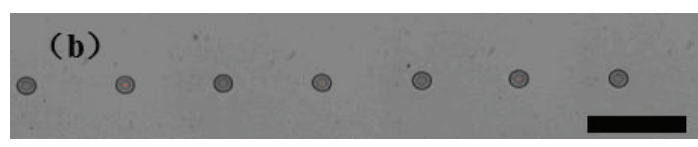

(b)

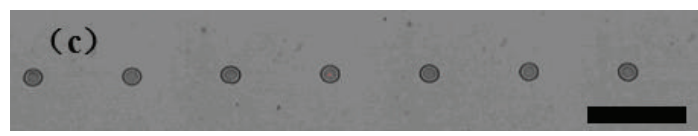

(c)

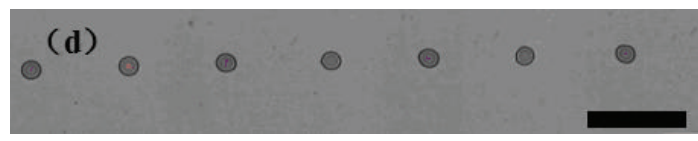

(d)

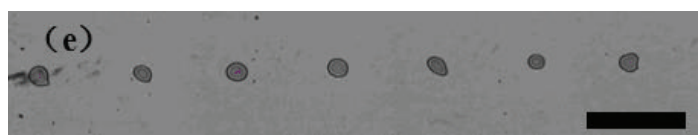

(e)

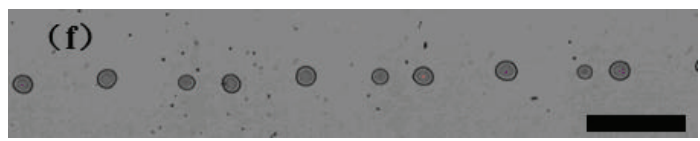

(f)

FIgURe 4: Printed droplets under AC voltage with different duty cycle $\rho$. Duty cycles were (a) $\rho=20 \%$; (b) $\rho=30 \%$; (c) $\rho=40 \%$; (d) $\rho=50 \%$; (e) $\rho=60 \%$; (f) $\rho=70 \%$. The collector motion speed was $v_{\text {col }}=10 \mathrm{~mm} / \mathrm{s}$. The scale bar is $1000 \mu \mathrm{m}$.

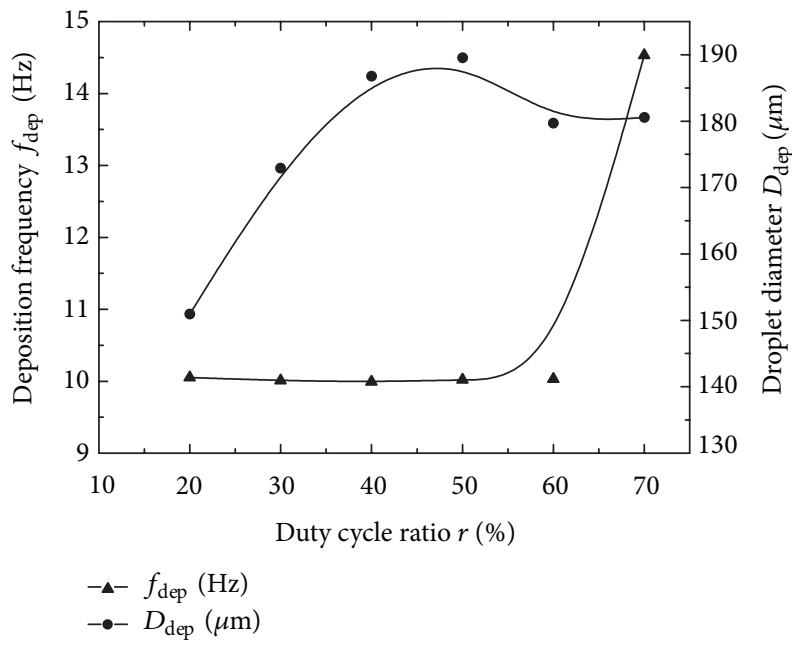

Figure 5: The relationship between deposition frequency $f_{\text {dep }}$, droplet diameter $D_{\text {dep }}$, and duty cycle $\rho$.

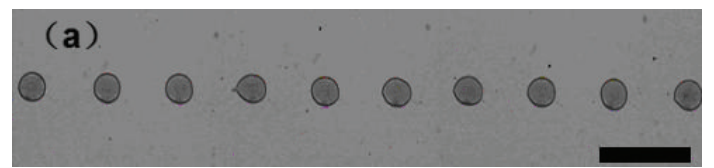

(a)

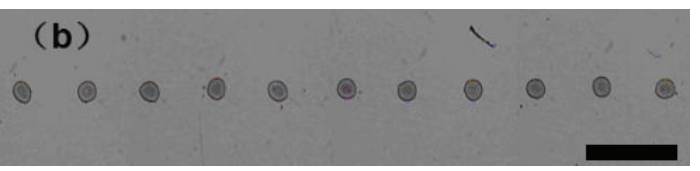

(b)

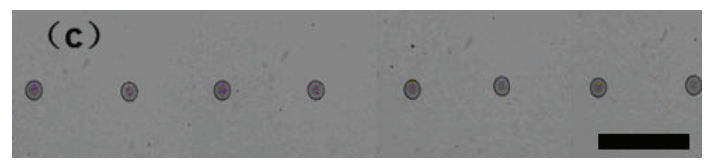

(c)

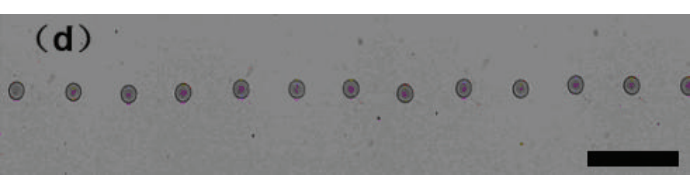

(d)

FIGURE 6: Printed droplets under AC voltage with different applied AC voltage frequency $f_{\text {app }}$. AC voltage frequency and collector motion velocity were (a) $f_{\text {app }}=10 \mathrm{~Hz}, v_{\text {col }}=4 \mathrm{~mm} / \mathrm{s}$; (b) $f_{\text {app }}=$ $30 \mathrm{~Hz}, v_{\text {col }}=10 \mathrm{~mm} / \mathrm{s}$; (c) $f_{\text {app }}=50 \mathrm{~Hz}, v_{\text {col }}=10 \mathrm{~mm} / \mathrm{s}$; (d) $f_{\text {app }}=70 \mathrm{~Hz}, v_{\text {col }}=10 \mathrm{~mm} / \mathrm{s}$. The scale bar is $1000 \mu \mathrm{m}$.

3.3. AC Voltage Frequency. The printed droplets deposited on the silicon collector with different AC voltage frequency $f_{\text {app }}$ of $10 \sim 70 \mathrm{~Hz}$ were shown in Figure 6. The PEO solution concentration $C$, solution supply rate $Q$, duty cycle $\rho$, negative AC voltage amplitude $U_{a}$, and positive AC voltage amplitude $U_{b}$ were $4 \mathrm{wt} \%, 20 \mu \mathrm{L} / \mathrm{hr}, 50 \%, 1.0 \mathrm{kV}$, and $2.8 \mathrm{kV}$, respectively. Higher frequency shortened the period of electric field alternation and accelerated breakup of microdroplets from the jet. Due to the constant solution supply rate, the droplet diameter $D_{\text {dep }}$ decreased with the increase of deposition frequency. As the applied AC voltage frequency $f_{\text {app }}$ increased from 10 to $70 \mathrm{~Hz}$, the deposition frequency $f_{\text {dep }}$ increased from 5 to $18 \mathrm{~Hz}$ and the droplet diameter $D_{\text {dep }}$ decreased from 280 to $150 \mu \mathrm{m}$; the relationship was plotted in Figure 7.

3.4. Solution Supply Rate. The printed droplets under different solution supply rate $Q$ were presented in Figure 8 . The PEO solution concentration $C$, duty cycle $\rho$, AC voltage frequency $f_{\text {app }}$, negative AC voltage amplitude $U_{a}$, and positive AC voltage amplitude $U_{b}$ were $4 \mathrm{wt} \%, 50 \%, 20 \mathrm{~Hz}$, $2.0 \mathrm{kV}$, and $2.8 \mathrm{kV}$, respectively. A higher solution supply rate can provide adequate printing materials to ensure the high speed injection of microdroplets with a larger diameter. The relationship in Figure 9 indicated that deposition frequency $f_{\text {dep }}$ increased from 10 to $22 \mathrm{~Hz}$ and the droplet diameter $D_{\text {dep }}$ increased from 170 to $185 \mu \mathrm{m}$, when solution supply rate $Q$ increased from $20 \mu \mathrm{L} / \mathrm{hr}$ to $60 \mu \mathrm{L} / \mathrm{hr}$. 


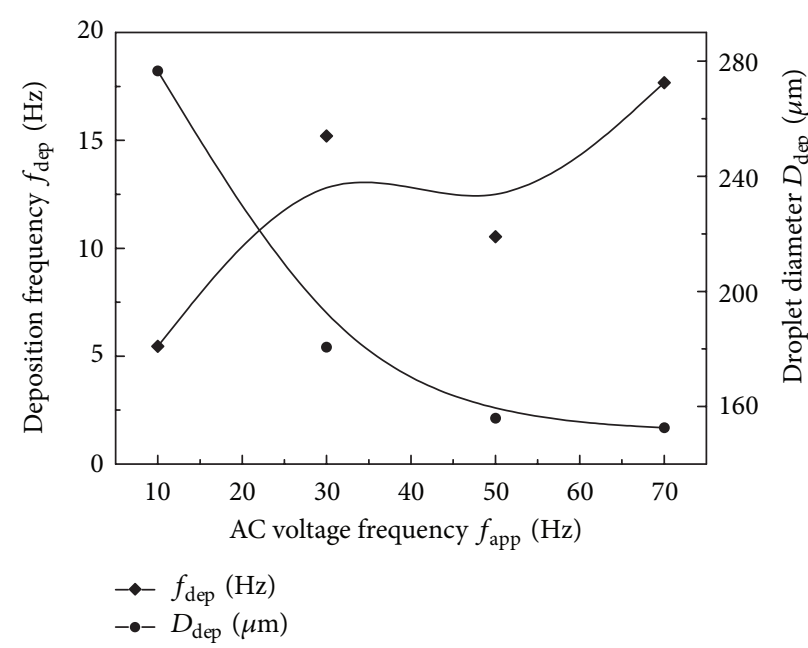

Figure 7: The relationship between deposition frequency $f_{\text {dep }}$, droplet diameter $D_{\text {dep }}$, and applied AC voltage frequency $f_{\text {app }}$.

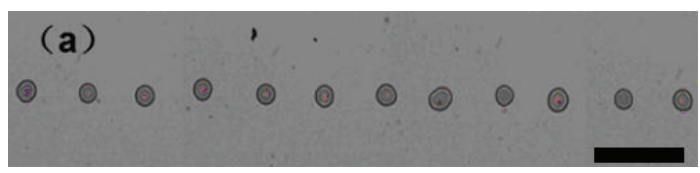

(a)

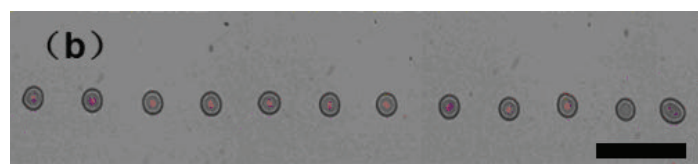

(b)

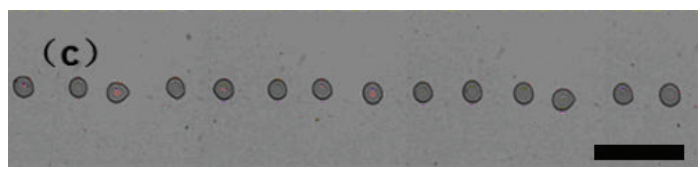

(c)

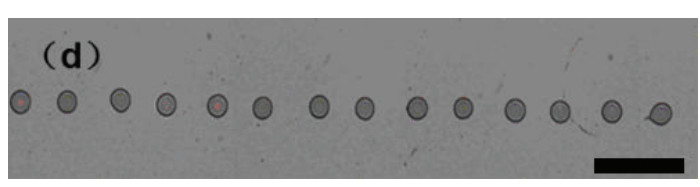

(d)

FIgUre 8: Printed droplets under AC voltage with different solution supply rate $Q$. Solution supply rate and collector motion speed were (a) $Q=20 \mu \mathrm{L} / \mathrm{hr}, v_{\text {col }}=6 \mathrm{~mm} / \mathrm{s}$; (b) $Q=30 \mu \mathrm{L} / \mathrm{hr}, v_{\text {col }}=6 \mathrm{~mm} / \mathrm{s}$; (c) $Q=50 \mu \mathrm{L} / \mathrm{hr}, v_{\text {col }}=10 \mathrm{~mm} / \mathrm{s}$; (d) $Q=70 \mu \mathrm{L} / \mathrm{hr}, v_{\text {col }}=10 \mathrm{~mm} / \mathrm{s}$. The scale bar is $1000 \mu \mathrm{m}$.

\section{Summary and Conclusion}

A novel EHDP method based on AC pulse voltage was utilized to orderly print microdroplets with a diameter of $100 \sim 300 \mu \mathrm{m}$ and a deposition frequency of $5 \sim 25 \mathrm{~Hz}$. AC pulse voltage led to the periodic alternation of electric field force applied on the charged jet. Positive voltage provided forward force to stretch the printing solution into fine jet and

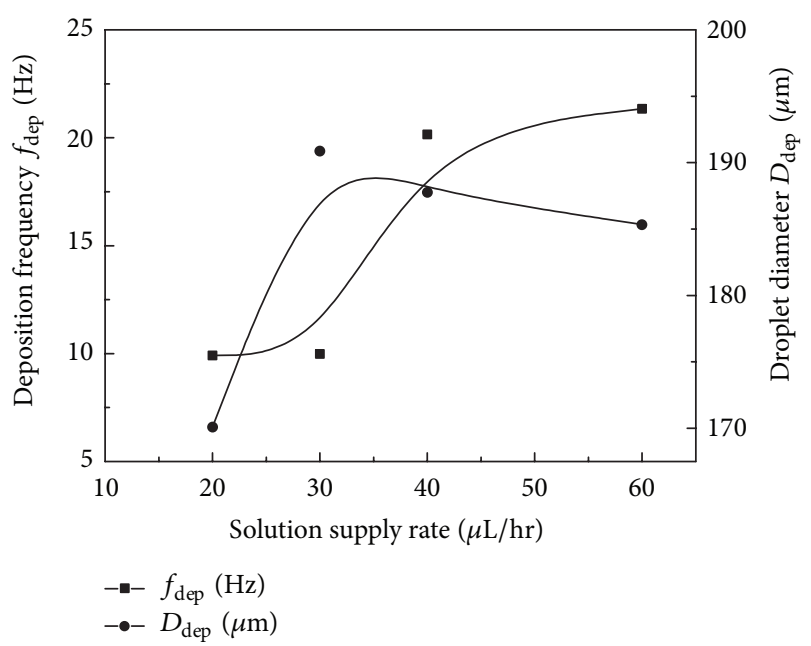

Figure 9: The relationship between deposition frequency $f_{\text {dep }}$, droplet diameter $D_{\text {dep }}$, and solution supply rate $Q$.

motion toward the collector. Reverse force that generated the negative voltage caused the charged jet to shrink back, which helps the charged jet break up into microdroplets. When the negative voltage was higher than $1 \mathrm{kV}$, the larger Weber number of jet motion might cause the charged jet to break into satellite dots and be deposited along the collector motion track. The number of satellite dots between two adjacent printed droplets increased with the increase of negative AC voltage amplitude. The effects of process parameters on the deposition frequency and droplet diameter were also studied. The deposition frequency increased with the increase of $\mathrm{AC}$ voltage frequency, while the droplet diameter decreased due to the constant solution supply rate. The deposition frequency and droplet diameter increased with the increase of duty cycle, but decreased with the increase of the solution supply rate.

The AC electric field varied charge transformation behaviors and decreased the charge density in the EHDP jet. This has opened a new door to study the control technology and accelerate the industrial application of EHDP.

\section{Conflict of Interests}

The authors declare that there is no conflict of interests regarding the publication of this paper.

\section{Acknowledgments}

This work is supported by a project funded by the National Natural Science Foundation of China (Grant no. 51305373, 51305084), the Natural Science Foundation of Fujian Province (Grant no. 2013J05083), and the Opening Fund of Guangdong Provincial Key Laboratory of MicroNano Manufacturing Technology and Equipment (Grant no. GDMNML2013-01). 


\section{References}

[1] P. Maury, D. Turkenburg, N. Stroeks et al., "Roll-to-roll UV imprint lithography for flexible electronics," Microelectronic Engineering, vol. 88, no. 8, pp. 2052-2055, 2011.

[2] T. Sekitani, U. Zschieschang, H. Klauk, and T. Someya, "Flexible organic transistors and circuits with extreme bending stability," Nature Materials, vol. 9, no. 12, pp. 1015-1022, 2010.

[3] N. Padma, S. Sen, S. N. Sawant, and R. Tokas, "A study on threshold voltage stability of low operating voltage organic thinfilm transistors," Journal of Physics D: Applied Physics, vol. 46, no. 32, Article ID 325104, 2013.

[4] Y. Li, "Molecular design of photovoltaic materials for polymer solar cells: toward suitable electronic energy levels and broad absorption," Accounts of Chemical Research, vol. 45, no. 5, pp. 723-733, 2012.

[5] N. Gao, W. Q. Liu, S. Q. Ma, Z. L. Yan, and Y. Zhao, "Modification of epoxy resin with cycloaliphatic-epoxy oligosiloxane for Light-Emitting Diode (LED) encapsulation application," Journal of Macromolecular Science B: Physics, vol. 51, no. 8, pp. 1509-1524, 2012.

[6] X. Xiao, T. Li, P. Yang et al., "Fiber-based all-solid-state flexible supercapacitors for self-powered systems," ACS Nano, vol. 6, no. 10, pp. 9200-9206, 2012.

[7] E. S. Kim, S. H. Kim, and C. H. Lee, "Electrospinning of polylactide fibers containing silver nanoparticles," Macromolecular Research, vol. 18, no. 3, pp. 215-221, 2010.

[8] S. Y. Lee, K. H. Choi, W. S. Choi et al., "Progress in flexible energy storage and conversion systems, with a focus on cabletype lithium-ion batteries," Energy and Environmental Science, vol. 6 , no. 8, pp. 2414-2423, 2013.

[9] G. Schwartz, B. C. K. Tee, J. Mei et al., "Flexible polymer transistors with high pressure sensitivity for application in electronic skin and health monitoring," Nature Communications, vol. 4, article 1861, 2013.

[10] J. H. Pikul, P. Graf, S. Mishra et al., "High precision electrohydrodynamic printing of polymer onto microcantilever sensors," IEEE Sensors Journal, vol. 11, no. 10, pp. 2246-2253, 2011.

[11] C. M. Xia, G. Y. Zhou, Y. Han, and L. T. Hou, "Photoluminescence of an $\mathrm{Yb}^{3+} / \mathrm{Al}^{3+}$-codoped microstructured optical fibre," Chinese Physics B, vol. 20, no. 8, Article ID 087802, 2011.

[12] P. Z. Zhang, R. S. Li, X. J. Pan, and E. Q. Xie, "Fabrication of $\mathrm{ZnO}$ nanoparticles-embedded hydrogenated diamond-like carbon films by electrochemical deposition technique," Chinese Physics B, vol. 22, no. 5, Article ID 058106, 2013.

[13] Q. Zheng, G. Fang, F. Cheng, H. Lei, P. Qin, and C. Zhan, "Lowtemperature solution-processed graphene oxide derivative hole transport layer for organic solar cells," Journal of Physics D: Applied Physics, vol. 46, no. 13, Article ID 135101, 2013.

[14] H. Ko, R. Kapadia, K. Takei, T. Takahashi, X. Zhang, and A. Javey, "Multifunctional, flexible electronic systems based on engineered nanostructured materials," Nanotechnology, vol. 23, no. 34, Article ID 344001, 2012.

[15] J. Lee, S. Chung, H. Song, S. Kim, and Y. Hong, "Lateral-crackfree, buckled, inkjet-printed silver electrodes on highly prestretched elastomeric substrates," Journal of Physics D: Applied Physics, vol. 46, no. 10, Article ID 105305, 2013.

[16] J. J. Bai, X. M. Wu, Y. L. Hua et al., "Efficiency of a blue organic light-emitting diode enhanced by inserting charge control layers into the emission region," Chinese Physics B, vol. 22, no. 4, Article ID 047806, 2013.
[17] B. D. Gates, "Materials science: flexible electronics," Science, vol. 323, no. 5921, pp. 1566-1567, 2009.

[18] D. F. Duarte Campos, A. Blaeser, M. Weber et al., "Threedimensional printing of stem cell-laden hydrogels submerged in a hydrophobic high-density fluid," Biofabrication, vol. 5, no. 1, Article ID 015003, 2013.

[19] M. Singh, H. M. Haverinen, P. Dhagat, and G. E. Jabbour, "Inkjet printing-process and its applications," Advanced Materials, vol. 22, no. 6, pp. 673-685, 2010.

[20] W. Li, G. Zheng, X. Wang et al., "Directly electrospun ultrafine nanofibres with Cu grid spinneret," Journal of Physics D: Applied Physics, vol. 44, no. 13, Article ID 135502, 2011.

[21] J. Zheng, Y. Z. Long, B. Sun et al., "Polymer nanofibers prepared by low-voltage near-field electrospinning," Chinese Physics $B$, vol. 21, no. 4, Article ID 048102, 2012

[22] Z. H. Zhang, Y. Z. Long, H. X. Yin et al., "Electrospun fluorescein/polymer composite nanofibers and their photoluminescent properties," Chinese Physics B, vol. 21, no. 9, Article ID 097805, 2012.

[23] D. Sun, C. Chang, S. Li, and L. Lin, "Near-field electrospinning," Nano Letters, vol. 6, no. 4, pp. 839-842, 2006.

[24] L. Xu and D. Sun, "Electrohydrodynamic printing under applied pole-type nozzle configuration," Applied Physics Letters, vol. 102, no. 2, Article ID 024101, 2013.

[25] W. W. Li, G. F. Zheng, X. Wang, and D. H. Sun, "Position deposition of electrospinning direct-writing nanofiber on pattern substrate," Optics and Precision Engineering, vol. 18, no. 10, pp. 2231-2238, 2010.

[26] G. Zheng, W. Li, X. Wang, D. Wu, D. Sun, and L. Lin, "Precision deposition of a nanofibre by near-field electrospinning," Journal of Physics D: Applied Physics, vol. 43, no. 41, Article ID 415501, 2010.

[27] K. H. Choi, A. Khan, K. Rahman, Y. H. Doh, D. S. Kim, and K. R. Kwan, "Effects of nozzles array configuration on crosstalk in multi-nozzle electrohydrodynamic inkjet printing head," Journal of Electrostatics, vol. 69, no. 4, pp. 380-387, 2011.

[28] V. D. Nguyen and D. Byun, "Mechanism of electrohydrodynamic printing based on ac voltage without a nozzle electrode," Applied Physics Letters, vol. 94, no. 17, Article ID 173509, 2009.

[29] L. Espín, A. Corbett, and S. Kumar, "Electrohydrodynamic instabilities in thin viscoelastic films-AC and DC fields," Journal of Non-Newtonian Fluid Mechanics, vol. 196, pp. 102-111, 2013.

[30] G. Larsen, R. Spretz, R. Velarde-ortiz, D. Vu, and L. Nunez, "Systems for producing multilayered particles, fibers and sprays and methods for administering the same," US Patent US 20130017148, 2013.

[31] R. Kessick, J. Fenn, and G. Tepper, "The use of AC potentials in electrospraying and electrospinning processes," Polymer, vol. 45, no. 9, pp. 2981-2984, 2004.

[32] S. Ghashghaie, A. M. Bazargan, M. E. Ganji et al., "An investigation on the behavior of electrospun $\mathrm{ZnO}$ nanofibers under the application of low frequency AC electric fields," Journal of Materials Science: Materials in Electronics, vol. 22, no. 9, pp. 1303-1307, 2011.

[33] L. Xu, X. Wang, T. Lei, D. Sun, and L. Lin, "Electrohydrodynamic deposition of polymeric droplets under low-frequency pulsation," Langmuir, vol. 27, no. 10, pp. 6541-6548, 2011. 
[34] S. A. Theron, E. Zussman, and A. L. Yarin, "Experimental investigation of the governing parameters in the electrospinning of polymer solutions," Polymer, vol. 45, no. 6, pp. 2017-2030, 2004.

[35] X. Sun, D. Jia, W. Kang, B. Cheng, and Y. Li, "Research on electrospinning process of pullulan nanofibers," Applied Mechanics and Materials, vol. 268, no. 1, pp. 198-201, 2013. 

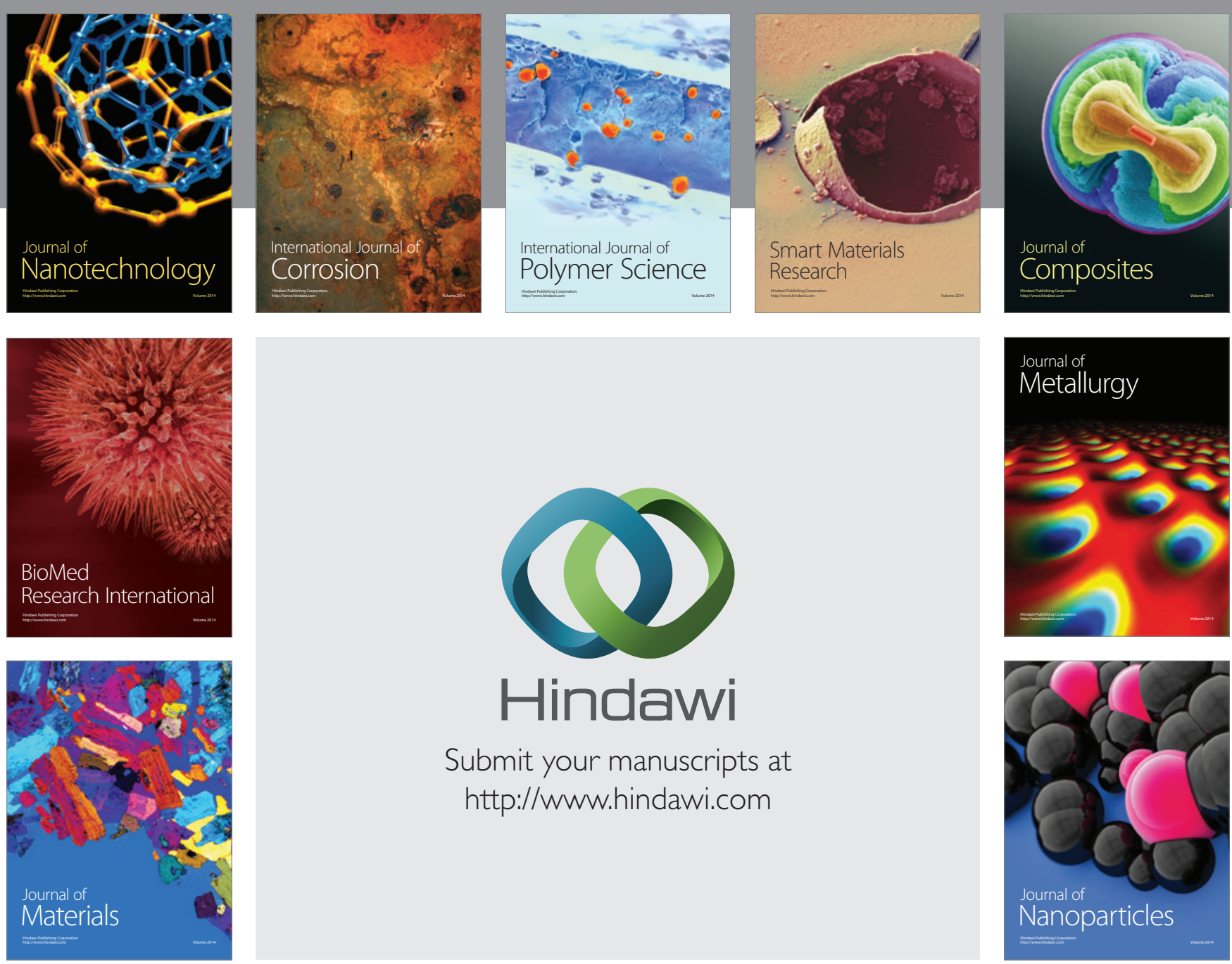

Submit your manuscripts at http://www.hindawi.com
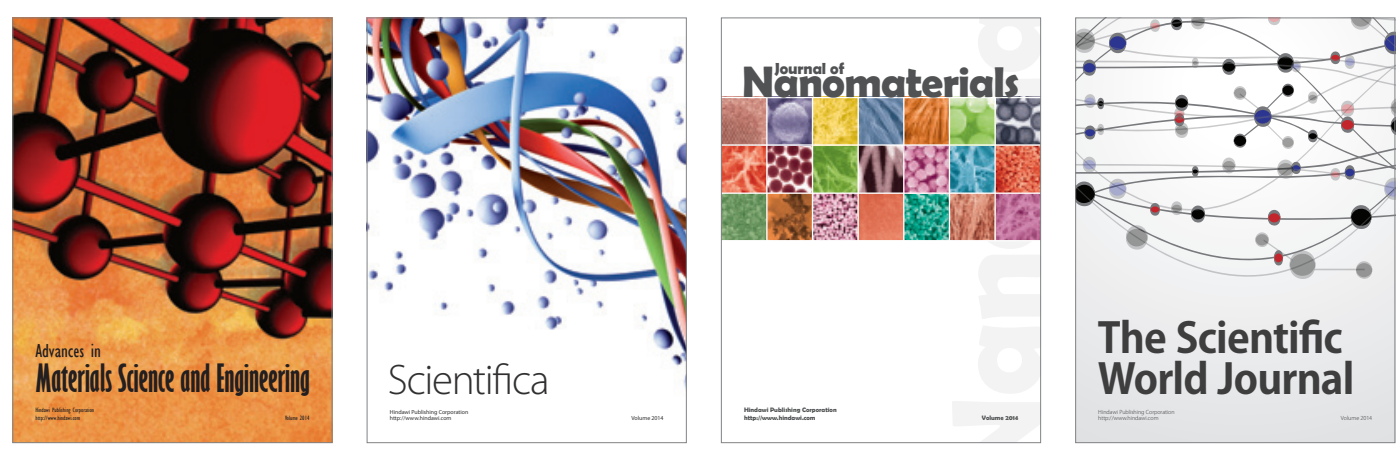

\section{The Scientific World Journal}
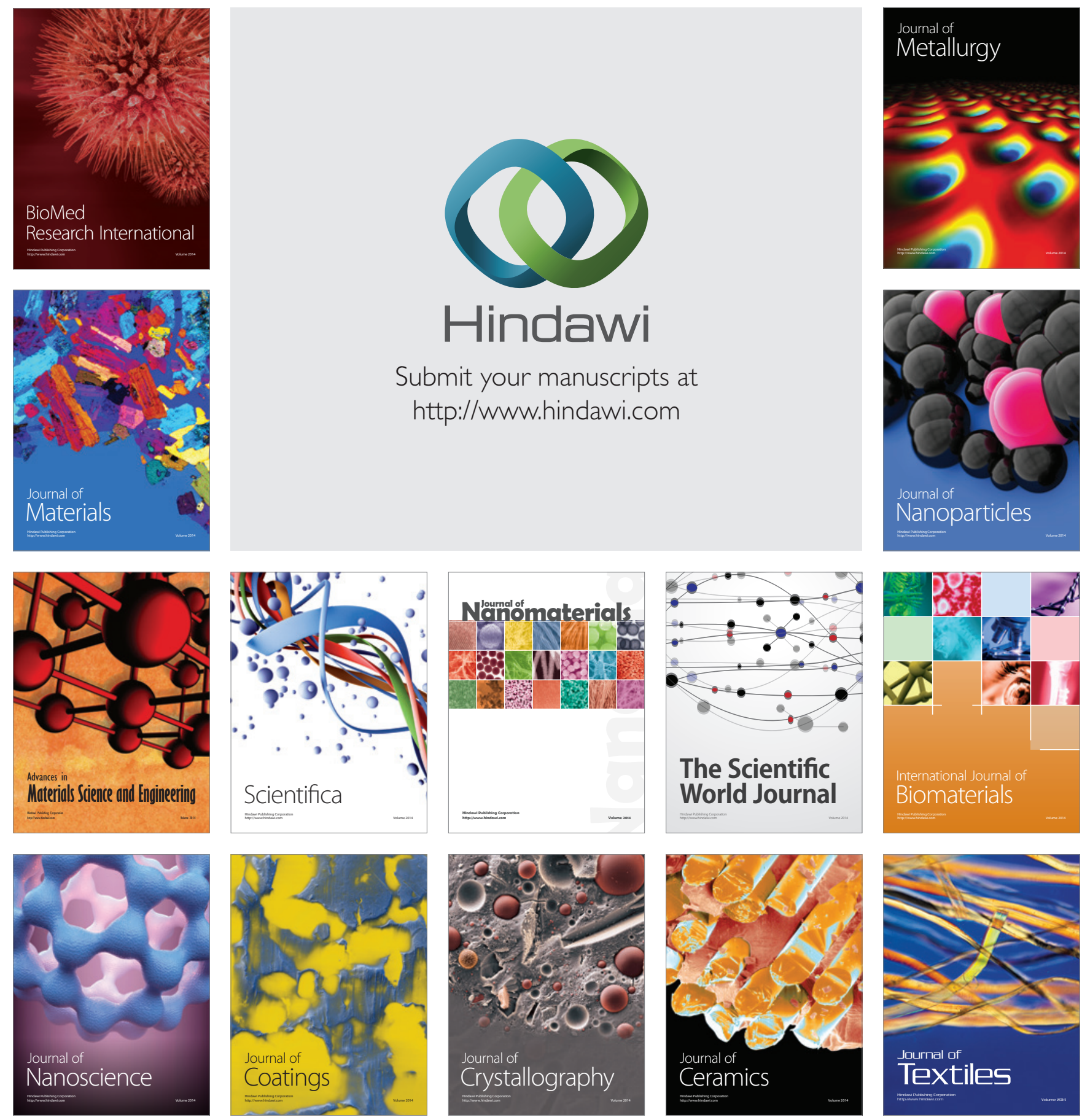